\title{
Liter per Milligram per Kilogram
}

National Cancer Institute

\section{Source}

National Cancer Institute. Liter per Milligram per Kilogram. NCI Thesaurus. Code

C120807.

A unit of concentration equal to liter divided by milligram per kilogram. 